\title{
Childhood onset mitochondrial myopathy and lactic acidosis caused by a stop mutation in the mitochondrial cytochrome c oxidase III gene
}

\author{
R Horváth, C Scharfe, M Hoeltzenbein, B H Do, C Schröder, R Warzok, S Vogelgesang, \\ H Lochmüller, J Müller-Höcker, K D Gerbitz, P J Oefner, M Jaksch
}

J Med Genet 2002;39:812-816

M ore than 100 mitochondrial (mt) DNA mutations have been described in association with different complex neurological disorders and with respiratory chain (RC) deficiency in the past decade. ${ }^{1}$ Aside from more frequently reported mt tRNA mutations and deletions, a growing list of pathogenic mutations affecting structural genes of mtDNA encoded respiratory chain subunits, mainly cytochrome b and cytochrome c oxidase subunit genes, has now been reported in association with various mitochondrial disorders as well ${ }^{2}$ and most of these mutations are thought to be of sporadic origin.

Cytochrome c oxidase (COX or complex IV), the terminal enzyme of the RC, catalyses the reduction of molecular oxygen by reduced cytochrome c. The complex is composed of 13 subunits. Three highly conserved mtDNA encoded subunits (COX I-III) form the catalytic core of the enzyme and the remaining 10 nuclear subunits are thought to modify or stabilise the complex. While the core forming subunits COX I and COX II contain the prosthetic groups and are known to play the most essential role in proton pumping and electron transfer, the function of COX III remains largely unknown. It is of interest that pathogenic mutations in mtDNA encoded subunits I-III have been identified whereas no mutations in the 10 nuclear genes are known so far. In contrast, numerous mutations in nuclear genes involved in the assembly of COX (SURF1, SCO2, SCO1, COX10) have been described. ${ }^{3}$ As with most mtDNA mutations, the clinical presentation of patients harbouring mutations in mt encoded COX subunit genes is highly variable, ranging from late childhood onset myopathy ${ }^{4-8}$ to severe childhood onset multisystem disorders, ${ }^{9-14}$ and this might be explained by the variable distribution and abundance of mutant mtDNA in different tissues and by different expression thresholds. ${ }^{3}$ All mt COX subunit gene mutations reported to date are heteroplasmic and most of these mutations have a high rate of mutant DNA in skeletal muscle and a lower or undetectable level of the mutation in other tissues, except for one patient who presented with Leigh-like syndrome, myopathy, and systemic COX deficiency ${ }^{10}$ and who carried a virtually homoplasmic frameshift mutation in COIII in all tissues investigated.

We report here a patient suffering from myopathy, lactic acidosis, exercise intolerance, and delayed growth with a heteroplasmic G9379A nonsense mutation (W58X) in the mtDNA encoded COIII subunit gene.

\section{PATIENTS AND METHODS}

\section{Case report}

The patient was the first of two children born to nonconsanguineous parents. The family history was negative for neurological disease. He developed normally until the age of 6 , when exercise intolerance was first noted. At the age of 10 he began to suffer from painful muscle cramps, fatigue, generalised muscle weakness, and shortness of breath. On examina-

\section{Key points}

- A novel heteroplasmic G9379A mutation, creating a premature stop in the COIII mitochondrial subunit of cytochrome c oxidase (COX), was found in a patient presenting with a relatively mild, childhood onset, slowly progressive myopathy with exercise intolerance, lactic acidosis, delayed growth, and with numerous ragged red fibres, lipidosis, and severe COX deficiency in skeletal muscle.

- Absence in leucocytes of the patient and of maternal family members points to a sporadic origin.

- Immunohistochemistry showed a decreased steady state level of COX subunits II/III in skeletal muscle, whereas staining of the nuclear encoded subunit IV was normal.

tion at the age of 14 his somatic growth was delayed (height between the 3rd and 10th centile, weight below the 3rd centile). At that time, neurological examination showed generalised mild muscle weakness, muscular hypotonia, and scapular winging. Deep tendon reflexes were weak and symmetrical. There was no clinical evidence of ophthalmoplegia or retinopathy. Brain MRI showed mild cortical and cerebellar atrophy with enlargement of the subarachnoid space, but without clinical manifestation. EMG showed myopathic changes with polyphasic low amplitude action potentials in several muscles. Nerve conduction studies and EEG were normal. Cardiological tests and echocardiogram showed no abnormalities.

Routine laboratory tests in serum were normal except for a marked lactate increase in serum especially after exercise (up to $12.8 \mathrm{mmol} / \mathrm{l}$, normal range $<2$ ), raised creatine kinase ( 101 $\mathrm{U} / \mathrm{l}$ normal range $<70$ ), free fatty acids $(1.43 \mathrm{mmol} / \mathrm{l}$, normal range 0.09-0.6), and beta-hydroxybutyric acid ( $1.32 \mathrm{mmol} / \mathrm{l}$, normal range 0.03-0.3). Blood carnitine levels and glucose tolerance test were also normal.

A recent follow up examination was performed at the age of 19 years. There had been rapid growth in the last two years (from $159 \mathrm{~cm}$ to $175.5 \mathrm{~cm}, 50$ th centile), but his weight is still very low ( $50 \mathrm{~kg}, 5 \mathrm{~kg}$ below the 5 th centile). Both muscle weakness and hypotonia are very slowly progressive (fig 1); the patient is still able to do 10 deep knee bends and walk four floors upstairs. No additional neurological symptoms and no episodes of myoglobinuria were noted.

Abbreviations: $m+D N A$, mitochondrial DNA; RC, respiratory chain; COX, cytochrome c oxidase; RRF, ragged red fibres; NCP, non-collagen protein; $C S$, citrate synthase 


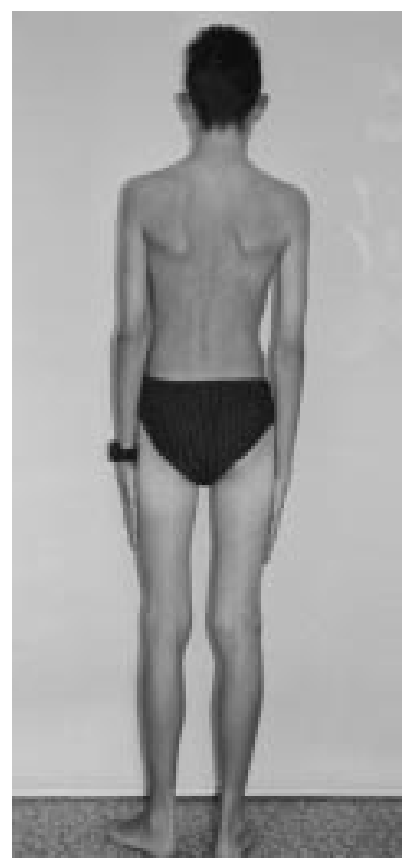

Figure 1 Photograph of the patient showing scapular winging and mild generalised muscular atrophy.

Morphology, immunohistochemistry, and biochemistry of skeletal muscle

At the age of 14 years, an open muscle biopsy of the quadriceps femoris was performed. Six $\mu \mathrm{m}$ serial cross sections were obtained for histochemical stains according to standard procedures. Immunohistochemistry using the ABC-Elite kit (DAKO) was done on paraffin embedded specimens. COX subunits II/III and IV were detected as previously described. ${ }^{15}$ A frozen part of the biopsy was used for biochemistry. RC complexes I-IV activities were determined in skeletal muscle as previously described. ${ }^{16}$

\section{DNA analysis}

DNA extraction from muscle and blood was done according to standard purification protocols (Qiagen, Hildesheim, Germany). We sequenced the complete mitochondrial genome from skeletal muscle DNA and compared it with the revised Cambridge mtDNA sequence. ${ }^{17}$

The G9379A mutation was quantified in total muscle DNA of the patient, hair follicle and blood DNA of the patient and his mother, and blood DNA of his sister by PCR and restriction digestion. A forward mismatch primer (5'ACTAACCATATACCAATGCT-3') creating a NheI restriction site in the presence of the mutation was used together with a reverse primer in np 9630-9605 in mtDNA. Resulting RFLPs were separated on a 3\% NuSieve agarose gel and were analysed by densitometry after ethidium bromide staining.

\section{RESULTS}

Skeletal muscle shows myopathy with ragged red fibres (RRF) and severe COX deficiency. Muscle biopsy showed signs of a chronic myopathy with fibre size variations but without necrosis. Approximately $50 \%$ of all fibres showed a ragged red appearance on Gomori trichrome staining as seen in mitochondrial myopathies (fig 2C). Vacuoles containing lipid storages were also observed in the majority of type II, but not type I fibres (fig 2D).

Histochemistry for COX showed a severe generalised decrease in all fibres (fig 2B). Biochemically, a severe reduction of COX activity was found (residual COX activity of $9 \%$ when related to gram non-collagen protein (NCP)) and with an even more severe decline when related to the highly increased mitochondrial marker enzyme citrate synthase (CS) (0.03 U
COX/U CS, normal range 0.90-4.70). The markedly increased activity of the mitochondrial marker enzyme CS (256 U/gNCP, normal range: 45-105) confirmed mitochondrial proliferation. Absolute activities of other RC complexes were normal when related to gram NCP but were reduced if normalised to CS. Total carnitine and free carnitine were markedly decreased in muscle (4.6 $\mu \mathrm{mol} / \mathrm{g}$ NCP, normal range $16.1-39$, and $3.4 \mu \mathrm{mol} / \mathrm{g}$ NCP, normal range 12.1-25.6), short chain acylcarnitine was normal.

Immunohistochemistry and immunoblotting of skeletal muscle point to severe reduction of COX II/III subunits Immunohistochemistry using a polyclonal antibody directed against the mitochondrially encoded subunits II/III showed a virtual absence of immunoreactivity (fig $2 \mathrm{~F}$ ) when compared to control muscle (fig 2E), whereas the nuclearly encoded subunit IV showed a normal level in the patient (fig 2G). An increased immunoreactivity in the subsarcolemmal zone owing to the accumulation of mitochondria was observed ( fig $2 G)$.

\section{DNA analysis shows a heteroplasmic stop mutation in COIII}

A mutational screening of the entire mtDNA showed 10 changes of which A4769G, C7028T, Al1251G, G11719A, A12612G, and G15737 are reported coding region sequence polymorphisms. ${ }^{1}$ In addition to the synonymous changes G1 1440A, Al 1653G, and Al4296G, a non-synonymous change G9379A was found leading to a stop codon in COIII. This mutation was not found in 268 controls. Electrophoresis showed a high rate (93\%) of the heteroplasmic G9379A point mutation in skeletal muscle, but not in white blood cells and hair follicles of the patient. Hair follicles and blood DNA of his mother and blood DNA of his sister were negative for the mutation (fig 3).

\section{DISCUSSION}

This is the fifth report of a newly found pathogenic mutation in the mt encoded COIII subunit gene. The mutation replaces a highly conserved tryptophan close behind the first predicted transmembrane domain by a stop codon (W58X).

Four different mutations have previously been described in COIII (table 1). Interestingly, despite significant declines of COX activity in skeletal muscle (10-20\% residual activity), which were comparable with those found in infantile lethal COX deficiency disorders and severe muscular hypotonia, ${ }^{3}$ both clinical outcome and muscle involvement of COX III deficient patients were relatively mild.

- A 15 bp microdeletion affecting a highly conserved region of COIII was detected with a high rate of heteroplasmy in skeletal muscle (97\%) and a very low rate in blood $(0.7 \%)$. The deletion was found to cause a severe decrease of COX activity and, interestingly, except for episodes of recurrent myoglobinuria triggered by viral illness, prolonged exercise, or decreased caloric intake, the muscle strength of the patient was normal. ${ }^{4}$

- A most likely sporadic mutation of postmitotic tissues was found in COIII (W249X) with a heteroplasmic rate of 57\% in muscle. This stop mutation was similarly described in association with a relatively mild phenotype with recurrent encephalopathy, myopathy, and exercise induced myalgia in a patient doing active sport as a middle distance runner until the first muscular symptoms occurred at the age of $17 .^{5}$ In this case, the relatively high proportion of remaining wild type molecules may explain the very mild phenotype and late onset.

- A systemic virtually homoplasmic frameshift mutation in COIII leading to a premature stop at amino acid position 111 was reported in association with an early onset, Leigh-like syndrome in a young girl. ${ }^{10}$ 

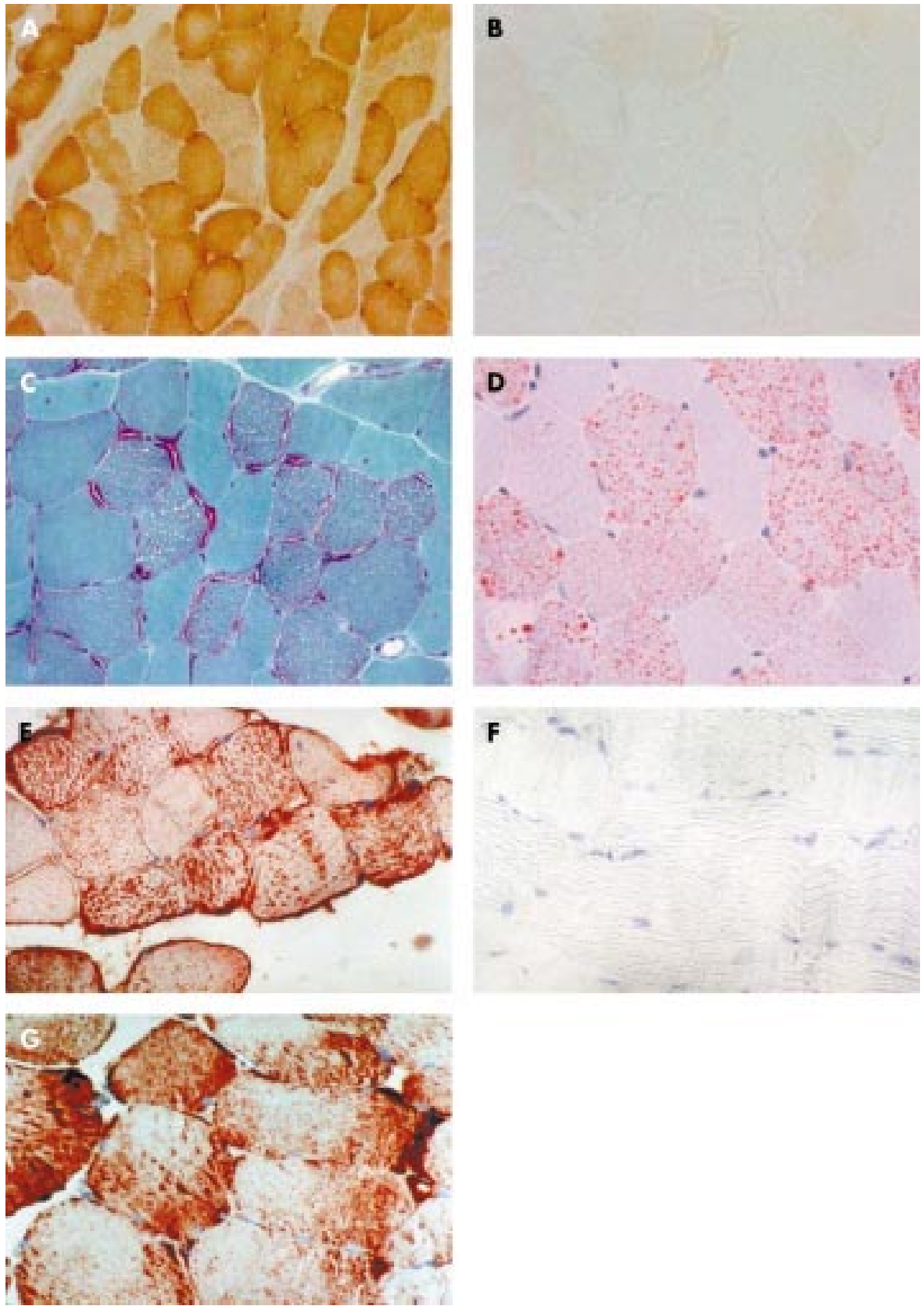

Figure 2 (A-D) Muscle histology of the patient shows severe COX deficiency in almost all fibres (B) compared to a normal control (A). On Gomori trichrome stain most of the type II fibres are ragged red $(C)$ and the same fibres contain marked lipid storage on oil red stain (D). (E-G) On immunohistochemistry, COX subunits II/III were lacking in all fibres of the patient (F) compared to a normal control (E). Subunit IV is regularly expressed in the patient's muscle (G).

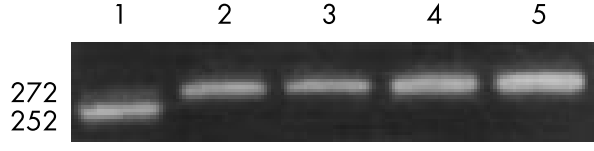

Figure 3 The mutation creates a Nhel restriction site (upper band wild type, lower band mutant). On gel electrophoresis the mutation was only present in the patient's muscle (lane 1), but not in his blood (lane 2). Blood DNA of two maternal relatives (lanes 3-4) and a control (5) were also negative for the mutation.

- A heteroplasmic missense mutation at np T9957C (F251L) was found systemically and has been described in association with childhood onset MELAS syndrome, but without a significant decline in COX activity. ${ }^{9}$
The mutation reported here is associated with severe COX deficiency ( $9 \%$ residual activity when related to protein and only $3 \%$ when normalised to CS), pointing to a most severe impairment of the multimeric enzyme. The marked RRF formation together with a three-fold increased activity of the mitochondrial marker enzyme CS point to a considerable mitochondrial compensatory mechanism. The mutation is heteroplasmic with a high rate of mutant (93\%) that is only present in skeletal muscle and consistent with this the COX stain showed an almost complete loss in all fibres (fig 2B).

We have detected the mutation in skeletal muscle but not in blood or hair follicles of the patient and his maternal relatives. This may point towards a sporadic and/or somatic origin; however, a mutation load below 3\% cannot be excluded with the methods used. This finding also confirms other reports on 


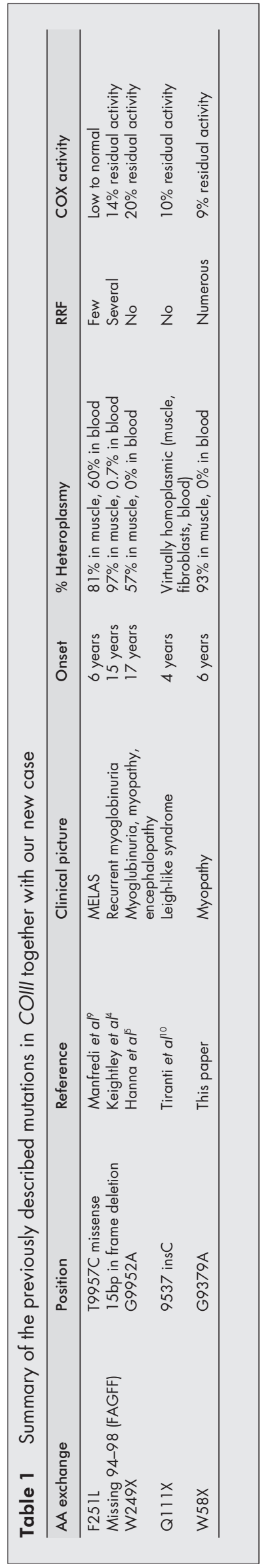

stop mutations in mt COX subunit genes, which were mostly restricted to skeletal muscle.

The clinical features in our patient partly resemble some of those described with another stop mutation in COIII (W249X) with mild proximal myopathy and exercise intolerance, ${ }^{5}$ but in contrast to the reported cases our patient presented with some novel findings on muscle morphology with a high amount of RRF (50\%) and a marked lipid accumulation, which was restricted almost exclusively to type II RRF (fig $2 \mathrm{C}, \mathrm{D}$ ). The amount of lipid accumulation causing remarkable vacuolisation in RRF is an unusual finding; however, other types of mitochondrial disorders have been reported in association with lipid storage owing to "secondary" carnitine deficiency, ${ }^{18-20}$ and this has also been observed in our patient (free carnitine concentration in muscle was $25 \%$ of normal). Defects of oxidative phosphorylation downstream of complexes I and II inhibit $\beta$ oxidation owing to decreased electron transfer from acyl-CoA dehydrogenases to ubiquinone and the intermediates of acyl-CoA $\beta$ oxidation are released from mitochondria as carnitine esters. ${ }^{21}$ Consistent with this, an abnormal lipid accumulation is repeatedly seen in patients with coenzyme $\mathrm{Q}_{10}$ deficiency. ${ }^{22}$

Functional studies on cybrids carrying other COIII mutations located $>36$ aa downstream from the mutation described here, which is the frameshift mutation leading to a stop at aa position 111 and the $15 \mathrm{bp}$ deletion (missing aa 94-98), confirmed a pathogenic role for both of these mutations with reduction, but not absence, of steady state levels of COX subunits I and II. ${ }^{1023}$ Two independently performed in vivo translation tests showed a clear absence of COX III polypeptide. ${ }^{102}$ In support of these findings we found a virtual absence of COX II/III subunits in skeletal muscle of the patient on immunohistochemistry when compared to a normal control (fig 2E, F).

Functional studies on cybrids containing the 15 bp deletion, which is predicted to remove the central region of the third $\mathrm{N}$-terminal membrane spanning region of COX III, have shown that only homoplasmic mutants failed to assemble the COX holoenzyme ${ }^{23}$ with no interaction of COX I-COX II and no detectable COX activity or ATP synthesis. In contrast, cells harbouring $97 \%$ of the mutant COX I and COX II subunits were assembled, despite a very low residual activity of COX of $6 \%$ and a rate of ATP synthesis of $9 \%$ of the normal. In support of this, cybrids carrying the frameshift mutation also indicated a role for COX III in assembly and stabilisation of the complex, as most of the nuclear encoded subunits were not assembled except COX IV, which is incorporated at an earlier step than COX III. Similarly, COX IV was present in our patient's muscle. Tiranti et al ${ }^{10}$ assumed that a mutant COIII might prevent the incorporation of the late subunits, which are rapidly degraded. ${ }^{10}$

Experiments on the COX enzyme from the bacterium Paracoccus denitrificans, which consists of four subunits only, showed that a COIII deletion leads to an accumulation of assembly intermediates of COX including a complex of subunits I and II and with free subunits I and II. Despite the absence of COX III, low but still significant COX activity was present. ${ }^{24}$

What might account for the relatively mild muscular symptoms of COIII mutations, when compared to other lethal infantile COX deficiency disorders with severe muscular hypotonia and similar decreased activity of complex IV?

In contrast to COIII stop or frameshift mutations, mutant loads exceeding $90 \%$ have not been described in the highly essential COI and COII subunit genes, ${ }^{78}{ }^{12} 14$ suggesting early deleterious effects. In this context, the most interesting finding is a single patient harbouring a systemically expressed, virtually homoplasmic frameshift mutation in COIII presenting with a relatively benign progressive Leigh-like syndrome, which similarly indicates a less important role for this subunit, when compared to COX I and COX II. ${ }^{10}$ It has been proposed 
that minimal residues of wild type mtDNA might compensate for the defect in a recessive manner. But if this is so, the biochemical findings do not entirely reflect the in vivo situation, which might involve different mechanisms in COX III deficiency to overcome muscular weakness. A residual COX activity of $10-20 \%$ owing to COIII mutations seems to affect skeletal muscle age dependently and to a minor extent (middle distance runner until the age of 17 , able to climb four flights of stairs at the age of 19 in our case), but a progressive accumulation of the deleterious mutation during postnatal life cannot be excluded.

In summary, our report of a new mitochondrial COIII mutation widens the spectrum of isolated COX deficiencies and helps in understanding the role of COX III in the functioning of the multimeric enzyme COX.

\section{ACKNOWLEDGEMENTS}

The first two authors contributed equally to this work. The excellent technical assistance of Anja Zimmermann, Diana Reinicke, and Sybille Galuschka and the clinical work of Professor Hans Röder, Professor Helga Wiersbitzky, and Dr Carol Macmillan are gratefully acknowledged. This work is supported by grants from the Deutsche Forschungsgemeinschaft Ja802/2-1 (MJ) and Scha811/2-1 (CS), the Ernst and Berta Grimmke Stiftung (MJ, RH), the Friedrich-Baur Stiftung (HL, MJ), and the NIH GM28428 (PJO).

\section{Authors' affiliations}

R Horváth, K D Gerbitz, M Jaksch, Metabolic Disease Centre Munich-Schwabing, Institutes of Clinical Chemistry, Molecular Diagnostics and Mitochondrial Genetics, Academic Hospital Schwabing, Munich, Germany

C Scharfe, B H Do, P J Oefner, Stanford University, Genome Technology Center, Palo Alto, CA, USA

M Hoeltzenbein, Institute of Human Genetics, Ernst-Moritz-Arndt University of Greifswald, Greifswald, Germany

C Schröder, Department of Paediatrics, Ernst-Moritz-Arndt University of Greifswald, Greifswald, Germany

R Warzok, S Vogelgesang, Institute of Pathology, Ernst-Moritz-Arndt University of Greifswald, Greifswald, Germany

H Lochmüller, Friedrich-Baur-Institut, Department of Neurology,

Ludwig-Maximilians-University, Munich, Germany

J Müller-Höcker, Institute of Pathology, LMU Munich, Germany

Correspondence to: $\operatorname{Dr} M$ Jaksch, Metabolic Disease Centre Munich-Schwabing, Institutes of Clinical Chemistry, Molecular Diagnostics and Mitochondrial Genetics, Academic Hospital Schwabing, Kölner Platz 1, 80804 München, Germany; Michaela.Jaksch@|rz.uni-muenchen.de

\section{REFERENCES}

1 MITOMAP: a human mitochondrial genome database. Center for Molecular Medicine, Emory University, Atlanta, GA, USA.

http://www.gen.emory.edu/mitomap.html, 2002

2 Hanna MG, Nelson IP. Genetics and molecular pathogenesis of mitochondrial respiratory chain diseases. Cell Mol Life Sci 1999;55:691-706.

3 Shoubridge EA. Cytochrome c oxidase deficiency. Am J Med Genet 2001;106:46-52.

4 Keightley JA, Hoffbuhr KC, Burton MD, Salas VM, Johnston WS, Penn AM, Buist NR, Kennaway NG. A microdeletion in cytochrome c oxidase (COX) subunit III associated with COX deficiency and recurren myoglobinuria. Nat Genet 1996;12:410-16.

5 Hanna MG, Nelson IP, Rahman S, Lane RJ, Land J, Heales S, Cooper M, Schapira AH, Morgan-Hughes JA, Wood NW. Cytochrome c oxidase deficiency associated with the first stop-codon point mutation in human mtDNA. Am J Hum Genet 1998;63:29-36
6 Rahman S, Taanman JW, Cooper JM, Nelson I, Hargreaves I, Meunier B, Hanna MG, Garcia JJ, Capaldi RA, Lake BD, Leonard JV, Schapira $\mathrm{AH}$. A missense mutation of cytochrome oxidase subunit II causes defective assembly and myopathy. Am J Hum Genet 1999;65:1030-9.

7 Comi GP, Bordoni A, Salani S, Franceschina L, Sciacco M, Prelle A, Fortunato F, Zeviani M, Napoli L, Bresolin N, Moggio M, Ausenda CD, Taanman JW, Scarlato G. Cytochrome c oxidase subunit I microdeletion in a patient with motor neuron disease. Ann Neurol 1998;43:1 10-16.

8 Karadimas CL, Greenstein P, Sue CM, Joseph JT, Tanji K, Haller RG,

Taivassalo T, Davidson MM, Shanske S, Bonilla E, DiMauro S. Recurrent myoglobinuria due to a nonsense mutation in the COX I gene of mitochondrial DNA. Neurology 2000;55:644-9.

9 Manfredi G, Schon EA, Moraes CT, Bonilla E, Berry GT, Sladky JT, DiMauro S. A new mutation associated with MELAS is located in a mitochondrial DNA polypeptide-coding gene. Neuromusc Disord 1995;5:391-8.

10 Tiranti V, Corona P, Greco M, Taanman JW, Carrara F, Lamantea E, Nijtmans L, Uziel G, Zeviani M. A novel frameshift mutation of the m+DNA COIII gene leads to impaired assembly of cytochrome $c$ oxidase in a patient affected by Leigh-like syndrome. Hum Mol Genet 2000;9:2733-42

11 Clark KM, Taylor RW, Johnson MA, Chinnery PF Chrzanowska-Lightowlers ZM, Andrews RM, Nelson IP, Wood NW, Lamont PJ, Hanna MG, Lightowlers RN, Turnbull DM. An mtDNA mutation in the initiation codon of the cytochrome $C$ oxidase subunit II gene results in lower levels of the protein and a mitochondrial encephalomyopathy. Am J Hum Genet 1999;64:1330-9.

12 Campos Y, Garcia-Redondo A, Fernandez-Moreno MA, Martinez-Pardo M, Goda G, Rubio JC, Martin MA, del Hoyo P, Cabello A, Bornstein B, Garesse R, Arenas J. Early-onset multisystem mitochondrial disorder caused by a nonsense mutation in the mitochondrial DNA cytochrome $\mathrm{C}$ oxidase II gene. Ann Neurol 2001:50:409-13.

13 Wong LJ, Dai P, Tan D, Lipson M, Grix A, Sifry-Platt M, Gropman A, Chen TJ. Severe lactic acidosis caused by a novel frame-shift mutation in mitochondrial-encoded cytochrome c oxidase subunit II. Am J Med Genet 2001; 102:95-9

14 Bruno C, Martinuzzi A, Tang Y, Andreu AL, Pallotti F, Bonilla E, Shanske S, Fu J, Sue CM, Angelini C, DiMauro S, Manfredi G. A stop-codon mutation in the human mtDNA cytochrome $c$ oxidase I gene disrupts the functional structure of complex IV. Am J Hum Genet 1999;65:61 1-20.

15 Müller-Höcker J, Droste M, Kadenbach B, Pongratz D, Hübner G. Fatal mitochondrial myopathy with cytochrome-c-oxidase deficiency and subunit-restricted reduction of enzyme protein in two siblings: an autopsy-immunocytochemical study. Hum Pathol 1989;20:666-72.

16 Fischer JC, Ruitenbeek W, Gabreels FJ, Janssen AJ, Renier WO, Sengers RC, Stadhouders AM, ter Laak HJ, Triibels JM, Veerkamp JH . A mitochondrial encephalomyopathy: the first case with an established defect at the level of coenzyme Q. Eur J Pediatr 1986;144:441-4.

17 Andrews RM, Kubacka I, Chinnery PF, Lightowlers RN, Turnbull DM, Howell N. Reanalysis and revision of the Cambridge reference sequence for human mitochondrial DNA. Nat Genet 1999;23:147.

18 Macmillan CJ, Shoubridge EA. Mitochondrial DNA depletion: prevalence in a pediatric population referred for neurologic evaluation. Pediatr Neurol 1996;14:203-10.

19 Dalakas MC, Leon-Monzon ME, Bernardini I, Gahl WA, Jay CA. Zidovudine-induced mitochondrial myopathy is associated with muscle carnitine deficiency and lipid storage. Ann Neurol 1994;35:482-7.

20 Munoz-Malaga A, Bautista J, Salazar JA, Aguilera I, Garcia R, Chinchon I, Segura MD, Campos Y, Arenas J. Lipomatosis, proximal myopathy, and the mitochondrial 8344 mutation. A lipid storage myopathy? Muscle Nerve 2000;23:538-42.

21 Munoz-Infante JP, Huszagh VA. Secondary carnitine deficiency and impaired docosahexaenoic (22:6n-3) acid synthesis: a common denominator in the pathophysiology of diseases of oxidative phosphorylation and beta-oxidation. FEBS Lett 2000;468: 1-5

22 Sobreira C, Hirano M, Shanske S, Keller RK, Haller RG, Davidson E, Santorelli FM, Miranda AF, Bonilla E, Mojon DS, Barreira AA, King MP, DiMauro S. Mitochondrial encephalomyopathy with coenzyme Q10 deficiency. Neurology 1997;48:1238-43.

23 Hoffbuhr KC, Davidson E, Filiano BA, Davidson M, Kennaway NG King MP. A pathogenic 15-base pair deletion in mitochondrial DNA-encoded cytochrome c oxidase subunit III results in the absence of functional cytochrome c oxidase J Biol Chem 2000/275: 13994-4003.

24 Haltia T, Semo N, Arrondo JL, Goni FM, Freire E. Thermodynamic and structural stability of cytochrome c oxidase from Paracoccus denitrificans. Biochemistry 1994;33:9731-40. 